\title{
Analysis of existing gender differences in the effect of using the Virtual Campus platform of the Politehnica University of Timisoara
}

\author{
Camelia Ciuclea* and Andrei Ternauciuc \\ Politehnica University of Timisoara, Romania
}

\begin{abstract}
Admitting the increasing interest for education delivered by the means of technology is relevant if we consider all the aspects, including features related to gender. Several studies point out that women and men differ in their way of interacting with technology, ICT being traditionally associated with men [1]. In the context of blended learning settings, there are several existing gender differences, which means a statistical analysis focused on differences between men and women users of the Virtual Campus platform is needed. The main objective of this study is to provide evidence of significant gender differences in the effect of using certain platform tools by both genders. A subsequent objective is to test if the efficiency of both manners of working with e-learning tools eventually converge around similar results (in case the results point to scarce differences). The research was conducted by looking at the final number of students following the Distance Learning program run by the eLearning Center at UPT, during the first semester of the academic year 2017-2018. Distance learning students enrolled at Politehnica University Timisoara are mostly digital natives, consumers of technology in order to support the teaching and learning processes. The aim of this paper is to analyze the gender differences in using the platform, based on the students' online activity statistics from Moodle and all the resulting data.
\end{abstract}

\section{Introduction}

The emergence of electronic learning (eLearning) was an inevitable consequence of the digital revolution, which began around the start of the $21^{\text {st }}$ century. It was possible because of all the innovations in information and communication technologies [2]. Back in the 1980's it worked as a form of Computer-Based Training but as universities opened towards delivering their programs and curricula, the eLearning phenomenon emerged. The name eLearning became a landmark only starting from 1999 [3].

In Romania, the educational system follows the European norms in terms of integrating ICT in order to improve the way information is delivered. The Politehnica University of Timisoara constantly adapts to the eLearning needs of the students and teachers. A prime example is including the Virtual Campus of the Politehnica University of Timisoara (CVUPT), a Moodle based eLearning platform, among its priorities. Many efficient

\footnotetext{
*Corresponding author: camelia.ciuclea@cm.upt.ro
} 
communication tools were installed, developed and tested in order to better connect teachers, students and administrative staff [4].

Politehnica University of Timisoara (UPT) introduced early on a blended learning system in order to supplement face-to-face interactions with electronic means of learning content delivery. Through the Distance Learning / Reduced Frequency and eLearning Center (CeL), UPT has developed an online educational environment for all the eLearning needs in the University, but mainly for the distance learning programs that it delivers since 2000 .

CeL has developed and adapted many eLearning solutions popular worldwide. Some of them fit the specifics of the Romanian educational system while others had to be reconsidered. The main benefits of integrating such tools are highly objective evaluating and self-evaluating methods, adaptability and freedom in teaching and learning, flexibility, effectiveness, creation of new virtual communities, stimulating creativity and interactivity.

Evolving from reproducing information to generating it, shifting the attention from teacher to student, from teaching to learning, from contents to results - it was all possible through certain communication tools: blog, wiki, forum, chat, audio-video conference, podcasting. The Moodle educational platform is preferred in Romania (and worldwide) for the facilities it offers and for the communication and teaching tools which it contains [5].

\section{Methodology}

The Virtual Campus platform functions as a communication interface between the administration, teachers and students, and integrates online learning with mobile learning modules for students from academic training courses through distance learning, as well as academic and administrative support for Master and PhD students (in a blended learning format). Therefore, the platform is constantly modified and enhanced, and every year the data is reorganized, reshaped and updated [6].

By analyzing the data that CVUPT can provide, we were able to conduct a case study in order to find if there are gender differences in using the Virtual Campus. This case study examines the results of some specific data extracted from the platform. In this paper, we aim to analyze whether there are significant differences between the users of CVUPT. The analysis is based on the extracted data that was filtered and processed by the criteria of gender.

There are no official or unofficial requirements for CVUPT users to provide information regarding their gender, therefore the gender repartition was done semi-automatically using query results exported from the platform and analyzed using Microsoft Excel. In order to preserve the users' privacy, only the ids of the users and their first names were initially exported. A list of unique first names was then manually assigned to the two categories, male and female, and based on this list, user ids were placed in the appropriate categories. All subsequent queries on the platform used these two separate lists of ids.

The manual placing of first names was possible due to the rather unambiguous nature of the Romanian language, however, cases where the gender was uncertain were removed from either list. Still, the human decision in this case is one of the biggest points of departure from scientific rigor, and further research will try to identify better ways to achieve the same goal, like using nature language processing (NLP) and gender identification algorithms.

We conducted the research by analyzing the number of students enrolled in the Distance Learning programs run by the eLearning Center of UPT during the first semester of the 20172018 academic year. We analyzed all target user interaction with the platform from September 2017 to February 2018.

From a total number of 660 users enrolled in the academic year 2017-2018 in Distance Learning studies at UPT, 201 are women and 459 are men (see Fig. 1: Gender repartition of the distance learning users). 
Because gender is a concept so complex in its dimensions, there are aspects not yet fully studied or even well understood. We started from the idea that every environment is one step far from being homogeneous because of certain aspects and details. Gender has already been identified as a significant status that affects participation in online learning and face-to-face collaboration, gender differences being a factor to be taken into account in the equation of learning [7]. Only a few previous studies conclude that there are differences in the aptitudes of students, in terms of gender. Whether they are behavioral or information processing differences these features are explained by social and biological factors [8]. While male students are easily approaching spatial problems, female students have richer verbal skills as well as in the field of computer activities - male students prefer games that require spatial reasoning, while women students choose digital games based on problem solving, graph interpretation, quantitative computations, according to a study developed by Lowrie and Jorgensen [9].

There is a lack of an abundant number of studies addressing the theme of e-learning versus gender differences. Still, they generally converge towards the same conclusion: that male students are more eager to use and learn computers than the female students. Related to the same topic, some authors conclude that men display more computer skills that their female colleagues (teenagers especially). [10] [11] [12]

Other research studies suggest that gender has no effect on satisfaction or attitudes towards e-learning ( [13], [14] ), or on teaching results ( [15] [16]).

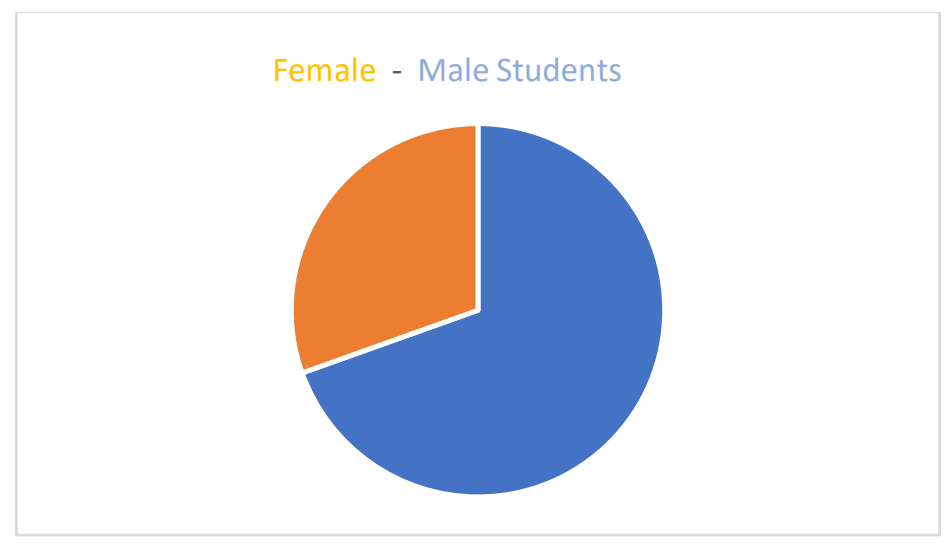

Fig. 1: Gender repartition of the distance learning users

Since gender has always played an important part in the delivering and processing of knowledge, information and skills, it seemed appropriate to exploit the experience we have as providers of e-learning and blended learning programs.

We conducted our research while considering possible (but not definite) differences. Only by the end of the research were we able to conclude certain observations.

The two hypothesis we had in mind focused on either:

- the absence of gender-marked cues in online learning environments. Equal participation of females and males in online-group work is encouraged [17]

- the existence of major differences in the manner of using the CVUPT platform. If this was the case, we aimed to propose some relevant changes/improvements to be implemented when adopting blended/distance learning systems, namely distance courses managed by the eLearning Center of UPT. 


\section{Results}

Although the students enrolled in the Virtual Campus are usually part of cohorts, without knowing anything other than their membership in a certain faculty/year of study, their activity is not perfectly homogeneous.

Since they originate from heterogeneous environments (geographical, social, educational, gender) it made us think of a possible case study that could analyze and interpret special aspects of their activity online, such as differences or similarities. We focused on aspects such as: the online activity, preferences, difficulties, frequency, number of hits sorted by the time of the day, type of course/activity, number of logins, resources, blog, forum, wiki view, comments/interventions to forum, number of uploaded documents.

A subsequent objective was to test if eventually the efficiency of both manners of working with e-learning tools converge around similar results (in case the results point to small differences).

The main aspects we looked into were: gender division of users, number of hits on the platform ("clicks" on any of the links or interaction elements, such as links or buttons), number of logins and absence of logins, number of assignments completed and no assignments, activity on the forums, number of posts, all of the above split by gender.

We have measured the number of hits and no hits on the platform, and the numbers pointed out the following results: while women performed a total of 190797 hits, men completed 433796 hits. The 190797 hits belonging to women users were completed by a total number of 201 women and the 433796 hits were done by 459 men.

\section{Total number of hits on CVUPT by gender}

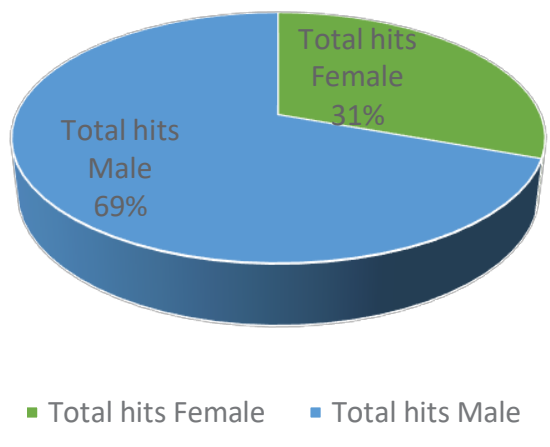

Fig. 2: Total number of hits on the CVUPT platform, according to gender

The situation is similar in the case of those who haven't scored any hit (no actions) on the Virtual Campus, with 2 out of 201 women and 5 out of 459 men. As percentages, these numbers represent $28.57 \%$ women users and $71.43 \%$ men users. 


\section{No hits on CVUPT}

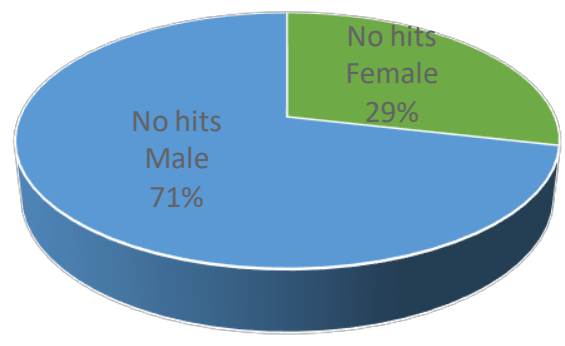

- No hits Female - No hits Male

Fig. 3: No hits on CVUPT

Out of the 660 users analyzed on the CVUPT, $30.28 \%$ of the logins belong to women (counting 17858 logins) and $69.72 \%$ to men (counting 41106 logins).

$41 \%$ of the women users logged in only once and never again, as well as $58.67 \%$ of the men.

\section{No logins on CVUPT}

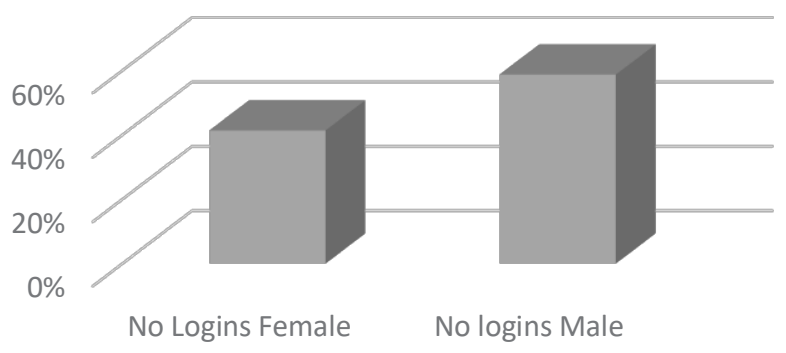

Fig. 4: No logins on CVUPT

In terms of assignments submitted, there were a total of 5275 submissions, out of which $29 \%$ were female and $71 \%$ male users. 


\section{Assignments Submitted}

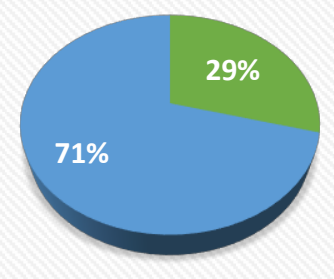

Assignments Submitted Female

Assignments Submitted Male

Fig. 5: Assignments submitted

We encountered a similar situation related to the activities on forums. Women created 43 posts, while men posted on forums 109 times. Therefore, from a total number of 152 posts, $28 \%$ were done by women and $72 \%$ by men.

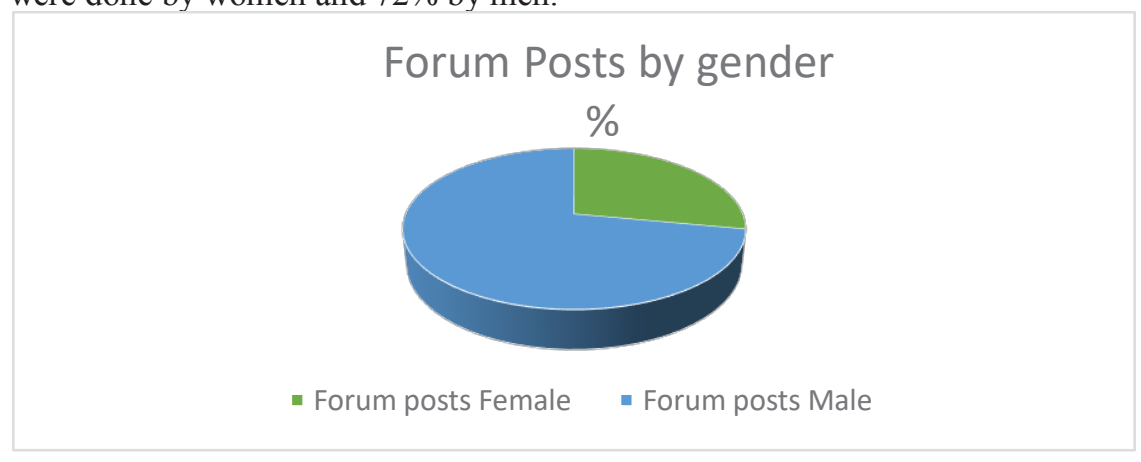

Fig. 6: Forum Posts by gender

The number of individual users who posted (once or multiple times) in forums on the platform was recorded at 82: 27 female and 55 male students, scoring 32\% (women) versus $67 \%$ (men).

\section{Conclusion}

This paper's main objective was to analyze the use of the CVUPT e-learning platform from the gender perspective, based on the students' online activity statistics from the platform and all the resulting data. This allows proposing some relevant changes/improvements to be implemented when adopting blended/distance learning systems. The case study wanted to answer the main following research question:

- Is there a significant difference between males and females in terms of the frequency of the activity online: frequency of logins, number of hits on the CVUPT, number of logins, uploaded assignments?

Based on the research question and the literature showing gender and culture effect on groups we hypothesized that there would be differences in the effect of using the Virtual 
Campus between female and male participants but all the results prove the contrary: there are mainly similarities around all the aspects followed by the research team. The numbers tend to remain proportionally constant, regardless of the aspect concerned.

To summarize, the results of this case study we conducted at Politehnica University Timisoara show:

- the users of the CVUPT platform tend to facilitate collaboration by creating a sense of belonging and learning community as well as the general tendency that characterizes learning, in general [18];

- communicating on the CVUPT creates a level of collaboration, and group formation. Groups are often formed by instructors based on their experiences, and criteria such as students' social skills and gender [19] [20];

- there were no major differences in the effect of using the Virtual Campus, but the matter is still to be researched [21].

A shortcoming of the data we had to work with was the lack of identical proportions in terms of the number of men versus women users. We had to work with numbers that were far from being similar: 201 women and 459 men. Hence, the results seem a little disproportionate. Although the figures are so different, the percentage proves otherwise: both men and women have had a similar average of the hits if we consider equal numbers as samples of the target group. Another possible improvement is the extension of this analysis towards a multi-year/multi-user research, involving more users and for a larger period of time.

The case study can become redundant, since the target group, the specializations, the criteria taken into account for the research - can leave room to further considerations. The team that developed the case study is involved in running the eLearning Center. Thus, the results of this research can be presented towards those involved in delivering education in UPT, but in a more conscious manner, addressing it to a heterogeneous public (in terms of gender as well).

\section{References}

[1] T. Adamus, M. Kerres, B. Getto and N. Engelhardt, "Gender and e-tutoring-A concept for gender sensitive e-tutor training programs," in 5th European Symposium on Gender and ICT Digital Cultures: Participation-Empowerment-Diversity, 2009.

[2] D. Andone and M. Frydenberg, "EXPERIENCES IN ONLINE COLLABORATIVE LEARNING WITH AUGMENTED REALITY," in eLearning \& Software for Education 2 (2017), 2017.

[3] S. Hubackova and I. Semradova, "Evaluation of blended learning," Procedia-Social and Behavioral Sciences, vol. 217, pp. 551-557, 2016.

[4] D. Andone, R. Vasiu and N. Robu, "Building a Virtual Campus for digital students," in IEEE Global Engineering Education Conference (EDUCON), Amman, 2011.

[5] R. Boateng, A. S. Mbrokoh, L. Boateng, P. K. Senyo and E. Ansong, "Determinants of e-learning adoption among students of developing countries," The International Journal of Information and Learning Technology,, vol. 33, no. 4, pp. 248-262, 2016.

[6] D. Andone, A. Ternauciuc and R. Vasiu, "Using Open Education Tools for a Higher Education Virtual Campus," in 2017 IEEE 17th International Conference on Advanced Learning Technologies (ICALT, Timisoara, 2017. 
[7] M. Augustinova, D. Oberle and G. L. Stasser, "Differential access to information and anticipated group interaction: impact on individual reasoning.," Journal of Personality and Social Psychology, vol. 88, no. 4, p. 619, 2005.

[8] S. Putrevu, "Exploring the Origins and Information Processing Differences Between Men," Academy of Marketing Science, vol. 2001, no. 10, 2001.

[9] T. Lowrie and R. Jorgensen, "Gender differences in students' mathematics game playing," Computers and Education, vol. 57, no. 4, pp. 2244-2248, 2011.

[10] C. Comber, A. Colley, D. Hargreaves and L. Dorn, "The effects of age, gender and computer experience upon computer attitudes," Educational Research, vol. 39, no. 2, pp. 123-133, 1997.

[11] N. Li and G. Kirkup, "Gender and cultural differences in Internet use: a study of China and the UK," Computers \& Education, vol. 48, pp. 301-317, 2007.

[12] B. Whitley, "Gender differences in computer-related attitudes and behavior: a meta-analysis," Computers in Human Behavior, vol. 13, no. 1, pp. 1-22, 1997.

[13] M. Cuadrado-García, M. Ruiz-Molina and J. Montoro-Pons, "Are there gender differences in e-learning use and assessment? Evidence from an interuniversity online project in Europe," Procedia Social and Behavioral Sciences, vol. 2, no. 2, pp. 367-371, 2010.

[14] M. Hung, C. Chou, C. Chen and Z. Own, "Learner readiness for online learning: scale development and student perceptions," Computers \& Education, vol. 55, pp. 10801090, 2010.

[15] R. Chu, "How family support and Internet self-efficacy influence the effects of elearning among higher aged adults - analyses of gender and age differences," Computers \& Education, vol. 55, pp. 255-264, 2010.

[16] R. Kay and L. Knaack, "A formative analysis of individual differences in the effectiveness of learning objects in secondary school," Computers \& Education, vol. 51, pp. 1304-1320, 2008.

[17] E. Koh and J. Lim, "Using online collaboration applications for group assignments: The interplay between design and human characteristics," Computers \& Education, vol. 59, no. 2, pp. 481-496, 2012.

[18] R. F. Kizilcec, "Collaborative learning in geographically distributed and in-person groups," in AIED 2013 Workshops Proceedings Volume (Vol. 67), 2013.

[19] S. Manske, T. Hecking, I. A. Chounta, S. Werneburg and H. U. Hoppe, Using differences to make a difference: a study on heterogeneity of learning groups., International Society of the Learning Sciences, Inc. [ISLS], 2015.

[20] R. Y. Bayeck, A. Hristova, K. W. Jablokow and F. Bonafini, "Exploring the relevance of single-gender group formation: What we learn from a massive open online course (MOOC)," British Journal of Educational Technology, vol. 49, no. 1, pp. 88-100, 2018.

[21] N. Ding, R. J. Bosker and E. G. Harskamp, "Exploring gender and gender pairing in the knowledge elaboration processes of students using computer-supported collaborative learning," Computers \& Education, vol. 56, no. 2, pp. 325-336, 2011. 